\title{
LA FORMACIÓN DE LA IDENTIDAD ABYECTA COMO UNA RESPUESTA ÉTICA DE CONTRACULTURA*
}

Fecha de recepción: 30 de marzo de 2014

Fecha de aprobación: 23 de abril de 2014

\section{Resumen}

En el presente texto, se analiza la novela Diario de Golondrina de A. Nothomb. Para ello, se acude principalmente a los modelos de análisis de la semántica interpretativa de F. Rastier y la semiótica del discurso de la escuela intersemiótica de Paris. El objetivo central de este trabajo es explicar el funcionamiento de la puesta en discurso de dicha novela, con el fin de evidenciar el sistema de valores subyacente y cómo este se opone a otros sistemas legitimados por ciertas formas de vida propias de la cultura moderna. Para ello, se estudiará la praxis enunciativa del narrador homodiegético protagonista; el cual constituye el punto de vista dominante que organiza el universo narrativo de la novela. Se buscará explicar que la intencionalidad de este narrador es perpetuar los valores de su sistema ético personal y universo cognitivo.

Palabras clave: Simulacro, autenticidad, cultura, naturaleza, vida, muerte, identidad, sensibilidad.

* Artículo de reflexión. Este texto se relaciona con los resultados obtenidos en el trabajo de investigación La inocencia, configuración semiótica de una nueva condición ético-existencial en la poética de Rómulo Bustos Aguirre. Dicho trabajo Hace parte del macroproyecto de investigación semiótica del Grupo de investigación Cultura y Narración en Colombia de la Escuela de Idiomas de la Universidad Industrial de Santander.

Citar: Chico Quintana, R. (julio - diciembre de 2014). La formación de la identidad abyecta como una respuesta ética de contracultura. La Palabra (25), 107-125.

\section{Rafael A. Chico Quintana}

Universidad Industrial de Santander, Colombia

Grupo de investigación

CUYNACO

rafachicoquintana@yahoo.es

Magíster en Semiótica de la Universidad Industrial de Santander, Profesional en Lingüística y Literatura de la Universidad de Cartagena. Investigador adscrito al Grupo de investigación CUYNACO. 


\title{
THE FORMATION OF AN EVIL IDENTITY AS A COUNTER - CULTURE ETHIC ANSWER
}

\begin{abstract}
The present text is an analysis of novel Diario de Golondrina by A. Nothomb. The analysis will be mainly supported on the theory of semiotic discourse analysis and François Rastier's interpretive semantics. In order to do so, firstly, an explanation is made of the mechanisms of configuration of the narrative universe of the novel. Secondly, it is shown how the narrator assesses that narrative universe and it is explained the structure of values system that support the praxis discursive of narrator. The objective of this analysis is to explain how this system establishes opposition to ethic's system of modern culture.
\end{abstract}

Keywords: Simulation, authenticity, culture, nature, death, live, identity, sensitivity.

\section{LA FORMATION DE L'IDENTITÉ ABJECTE EN TANT QUE RÉPONSE ÉTHIQUE DE CONTRECULTURE}

\section{Résumé}

Dans ce travail, on analyse le roman Journal d'Hirondelle de A. Nothomb. Pour y arriber, on fait recours principalement aux modèles d'analyse de la sémantique interprétative de F. Rastier et à la sémiotique du discours de l'école intersémiotique de Paris. L'objectif central de ce travail est celui d'expliquer le fonctionnement de la mise en scène du discours de ce roman-là, afin de mettre en évidence le système de valeurs subjacent et comment celui-ci s'oppose à d'autres systèmes légitimés par certaines formes de vie propres de la culture moderne. Pour cela, on étudiera la praxis énonciative du narrateur homodiégétique protagoniste ; ceci constitue le point de vue dominant qui organise l'univers narratif du roman. On cherchera à expliquer que l'intentionnalité de ce narrateur est celui de perpétuer les valeurs du système éthique personnel et de l'univers cognitif.

Mots clés: Simulacre, authenticité, culture, nature, vie, mort, identité, sensibilité. 


\section{Presentación}

Lo que es aceptable en la conducta, lo que se valora como estimable en el proceder es siempre un deber-ser instaurado en el espacio-tiempo de una cultura particular. Un borde trazado que circunscribe el "área" donde ha de construirse lo legítimo en materia de identidad. Es por ello que el actor social debe vérselas con modelos establecidos y debe configurar su personalidad en relación a ellos (Cuche, 2002, pp. 45 - 48). Sin embargo, con esto, se establece una tensión dialéctica entre el ser como individuo y los parámetros prefijados por la cultura. Explica Denys Cuche (2002, p. 47) que, pese a esa homogeneidad impuesta por lo que Linton llama "personalidades de base", es imposible negar que la diversidad caracterológica anida en el espacio-tiempo del escenario cultural. Ello equivale a decir que cada sujeto asume una forma de ser diferente dentro del común de la norma. A esto, se le puede llamar competencia adaptativa de los actores sociales y constituye una habilidad altamente estimada dentro del marco de las dinámicas y procesos ligados a la intersubjetividad. Lo cual explica que la "anormalidad psicológica pre- sente y estigmatizada en toda sociedad" se define fuera de tales fronteras (Cuche, 2002, p. 47), lo mismo que el crimen y la inmoralidad; por ende, que los sistemas sociales tengan instituciones especializadas para todas estas marginalidades, llámense clínicas de reposo, cárceles, albergues, etc., resulta muy poco sorprendente. Pero, más allá del valor negativo dado a estas personalidades marginales, ¿pueden, ellas, instituirse, en el campo de las representaciones discursivas, como opciones de respuesta ética frente a los sistemas de valores que gobiernan una colectividad y una cultura? A este cuestionamiento, es a lo que se intenta dar respuesta en el presente trabajo; pero, cabe anotar que el interés por una problemática como esta no se restringe a los objetivos de un análisis puntual.

Si bien es innegable que el corpus estudiado aquí lo compone una novela, las conclusiones derivadas entran en diálogo con los intereses de una línea de investigación personal ligada a unas preferencias teórico-metodológicas. En cuanto a esas preferencias, se matriculan con los presupuestos de la semiótica del discurso y la semántica interpretativa. Se pretende en este artículo poner en juego el instrumental de estos modelos con miras a la dilucidación de la ya mencionada respuesta, pero en afán de derivar unas conclusiones $\mathrm{o}$, como se verá más adelante, algunas preguntas investigativas, relacionada con el problema macro de cómo los sistemas éticos reguladores de las relaciones intersubjetivas toman forma en la enunciación literaria.

Si bien es cierto que se busca aportar a un interés personal, lo es también que, dada la pertenencia de este trabajo a los campos de la investigación literaria y del análisis semiótico de los discursos, tales aportes, aunque pequeños, proponen la pista de un elemento clave: los modos en los cuales ciertas formas de vida propias de la modernidad occidental categorizan las relaciones sociales, lo vínculos éticos y los objetivos perseguidos por lo actores sociales, de tal manera que lo entendible en determinados contextos ideológicos como antivalor (hipocresía, deshonestidad, etc.) es reinterpretado positivamente. Esto hace parte del objeto de estudio de una investigación mayor que inició con el análisis de la obra poética de un autor colombiano, Rómulo Bustos Aguirre (Chico, 2013); por

1 Cabe advertir que no es pretensión del presente trabajo caer en un reduccionismo que niegue la riqueza y complejidad de un texto que ofrece múltiples puntos de aproximación y objetos de análisis. Simplemente, se ha querido focalizar uno de esos aspectos. 
ahora, como ya se dijo, este trabajo es un intento de explorar una arista del problema macro en un corpus diferente al de la ya mencionada obra.

\section{El trasegar de lo abyecto}

La respuesta al cuestionamiento acerca de si las formas socialmente inaceptables del ser pueden instituirse, en el campo de las representaciones discursivas, como opciones de respuesta ética frente a otros sistemas de valores que gobiernan una colectividad y una cultura parece gravitar en la novela de Amélie Nothomb (2006). Una tensión soporta su recorrido narrativo. Configura la beligerancia de un sistema de valores opuesto a las normatividades y modelos sociales, algo que se manifiesta a manera de coqueteo voluntario con lo abyecto o la empresa personal de un actor, cuyo punto de vista y concepción del mundo se encuentra fuera de toda ética convencional. "La ideología es lo que persuade a hombres y mujeres a confundirse mutuamente de vez en cuando por dioses o por bichos", dice Eagleton (1991, p. xiii). En la novela de Nothomb, esto se presenta bajo la forma de una gradual revelación, desde el presentimiento hasta la certeza de la expiación: "Acepto morir para proteger un misterio que se me escapa. No tendré explicación: es un acto de fe" (Nothomb, 2006, p. 103).

En relación a lo anterior, se pretende aquí seguir un recorrido interpretativo focalizado en la figura del protagonista. El sincretismo entre enunciador y actor protagonista, planteado desde inicios de la narración, autoriza tal restricción de lectura. ${ }^{1}$ Enunciando en primera persona, el narrador protagonista configura el universo del relato en función de su singular punto de vista. Este se caracteriza por estar determinado por una motivación básica: un querer-ser y hacer en conflicto rampante con el sistema de valores imperante en el universo cultural donde se inscriben sus acciones. Dentro de esta polémica, este actor de lo abyecto experimenta voluntariamente varias transformaciones en la configuración de su identidad. Ahora bien, desde la perspectiva que rige el presente trabajo, se piensa que ello es producto de una especial convicción del narrador; lo que explicaría el origen de la motivación y el porqué de esas transformaciones.

El actor -llamado aquí, por comodidad metodológica, el protagonista -nunca enuncia su nombre, el que le perteneciera por asignación en registros o documentación legal. Inicia contextualizando en la peculiaridad de su historia. Cosa que es notoria con la enunciación de su rechazo a ser reconocido bajo toda coordenada de identidad socialmente aceptada: "En realidad, dedicamos todo nuestro tiempo a luchar contra el terror de lo vivo. Inventamos definiciones para huir de él: me llamo tal, tengo un curro allí, mi trabajo consiste en hacer esto o lo otro" (Nothomb, 2006, p. 8). Se notará la inmediata oposición entre los conceptos de vida e identidad social. El sintagma "dedicamos todo nuestro tiempo a luchar contra el terror de lo vivo" implica valoración negativa respecto al acto de rehuir de ese terror $y$, por presuposición lógica, el evaluar este último como un valor deseable. Un enunciado brinda muestras adicionales de ello: "Con más agudeza aún, ya que se trata del único equipaje que tenemos, sabemos lo siguiente: estamos vivos. ¿En qué consiste la vida en esta fracción de segundo durante la cual tenemos el raro privilegio de carecer de identidad?" (Nothomb, 2006, p. 7). Dice el protagonista $y$, con ello, resemantiza algo que ordinariamente sería, a la vez, un exabrupto y un desatino en todo sistema cultural y orden social: el carecer de identidad. Sin embargo, esto, para él, es un privilegio, ya que el tenerla está ligado al nombre propio, poseer bienes y tener ocupación laboral: "me llamo tal, tengo un curro allí, mi trabajo consiste en hacer esto o lo otro" 
(Nothomb, 2006, p. 8). Desde la perspectiva de este narrador, la vida es el carecer de identidad, lo cual define el caso contrario como sinónimo de la muerte. De la tensión de este par de sememas (vida / muerte), depende la estructura narrativa. A su vez, en dicha estructura, el protagonista establece un plan de acción con un objetivo central que subsume otros tres planes o programas narrativos. Estos últimos remiten a las transformaciones experimentadas por dicho actor.

El primero de estos es deducible de la oposición antes descrita. Se trata de las acciones animadas por la vocación de anonimato profesada por el actor, su renuencia a ser definido bajo las coordenadas culturales del nombre propio, la posesión de bienes y la ocupación laboral. El protagonista busca librarse de la identidad social asignada, pero la realización de tal objetivo le demanda insensibilizarse:

Entonces decidí matar mis sensaciones. Me bastó con encontrar el conmutador interior y oscilar en el mundo del ni frío ni calor. Fue un suicidio sensorial, el comienzo de una nueva existencia. Desde entonces, ya no tuve dolor. Ya no tuve nada. La capa de plomo que bloqueaba mi respiración desapareció. El resto también. Vivía en una especie de nada (Nothomb, 2006, p. 9).

\section{Más delante afirma:}

La música que antes me conmovía ya no me provocaba reacción alguna, incluso sensaciones básicas, como comer, beber, darme un baño, me dejaban indiferente. Estaba castrado por todas partes. La desaparición de los sentimientos no me pesó. Al teléfono, la voz de mi madre sólo era una molestia que me hacía pensar en un escape de agua. Dejé de preocuparme por ella. No estaba mal. Por lo demás las cosas no marchaban bien. La vida se había convertido en muerte (Nothomb, 2006, p. 10).

$\mathrm{Su}$ "nada" de indiferencias es "comienzo de nueva existencia", pero la transformación conlleva al despoje de su capacidad para experimentar sentimientos hacia los valores ofrecidos por el universo cultural; sin embargo, lejos de toda preocupación, el protagonista avanza en sosiego hacia la total anestesia: "Estaba castrado por todas partes. La desaparición de los sentimientos no me pesó" (Nothomb, 2006, p. 10). A estas alturas, el actor ha perdido, además, competencia para valorar, puesto que la insensibi- lidad le sustrae de todo compromiso emocional: "la vOz de mi madre sólo era una molestia que me hacía pensar en un escape de agua. Dejé de preocuparme por ella. No estaba mal" (Nothomb, 2006, p. 10). Estando así, el universo cultural es cosificado al grado de perder hasta los nexos parentales con el protagonista. Ello se aprecia con la anulación de la investidura del actor madre, quien pierde el valor emocional que le ligaba al protagonista.

En este punto, se hace necesaria una precisión. La devaluación de la madre es tan sólo el clímax de una cadena de disjunciones que empieza con la necesidad de librarse del dolor frente al fracaso amoroso y la vergüenza por sentirlo: "Acababa de vivir una decepción amorosa tan estúpida que ni siquiera merece la pena hablar de ello. A mi sufrimiento había que sumarle la vergüenza del propio sufrimiento. Para prohibirme semejante dolor, me arranqué el corazón" (Nothomb, 2006, p. 9). Seguirá, luego, con la disjunción de la pena residual y la vergüenza. El medio utilizado para ello lo declara él mismo: "Decidí matar mis sensaciones". Esto permite reconocer la equivalencia semántica entre los semas ${ }^{2} \mathrm{~d} o-$

2 Rastier define identidad sémica como la semejanza semántica entre rasgos de diferentes sememas. (2005, 63-64)

3 En su teoría semántica interpretativa François Rastier propone un sistema categorial que agrupa los rasgos semánticos (semas) definitorios de una acepción (semema) en clases semánticas. Estas clases se encuentran jerarquizadas en función de su mayor inclusividad. El taxema se ubicaría sobre el semema, incluyéndolo. (2005, pp. 19-68) 
lor, vergüenza, pena y madre, lo que hace válido proponer una única categoría semánticamente abarcadora: ${ }^{3}$ elementos del universo cultural. Dado esto, todas las acciones del protagonista estarían ligadas a una única estructura, variando sólo en el grado de eliminación del valor emocional.

A estas alturas, la pérdida voluntaria de la competencia axiológica es evidente y lo primero que se infiere es la degradación ética acompañada de la incontenible anestesia. La cuestión es relativa. Más bien, se está ad portas de la configuración de una nueva condición del ser. En primer lugar, la insensibilización conduce al desplazamiento de la componente tímica, pues el protagonista afirma: "Por lo demás las cosas no marchaban bien. La vida se había convertido en muerte" y antes, "Superado el alivio, empecé a aburrirme de verdad" (Nothomb, 2006, p. 9). El proceso ha conducido a la disforia, posicionando al protagonista en lugar de expectativa, ya que un estado disfórico presupone un posible momento de euforia que le suplante:

Lo que activó el mecanismo fue un disco de Radiohead. Se llamaba Amnesiac...Lo escuché y no experimenté nada. Aquel era el efecto que, en adelante, me producía cualquier música. Ya empezaba a encogerme de hombros... cuando llegué a la tercera canción... A priori, no había nada conmovedor en ello, pero descubrí, situada en la comisura del ojo una lágrima (2006, pp. 10-11).

Se abre la puerta a la búsqueda de nuevos tipos de sensibilidad. El sujeto ha desplazado su competencia hacia horizontes necesariamente incompatibles con los del común de la sociedad. Sobre su gusto por este trabajo de Radiohead un actor, del que se hablará más adelante, enuncia desaprobación: " $\mathrm{O}$ h, hasta dónde puede llegar el esnobismo!" (Nothomb, 2006, p. 40). Si la madre es la puerta de salida y etapa final de la cosificación, la singularidad de esta preferencia musical es la entrada a un mundo donde se encontrará la vida que en el universo cultural rechazado se ha tornado en muerte: "Por lo demás las cosas no marchaban bien. La vida se había convertido en muerte" (Nothomb, 2006, p.10).

El término esnobismo resulta bastante significativo. Según el Diccionario de la Real Academia Española (DRAE), la condición esnob es la del sujeto que imita las maneras y opiniones de aquellos que consideran distinguidos. La simplificación propia de esta definición resulta heurística. Semas clave resaltan en ella: simulación, falsedad, distinción social; pero, es necesario acceder a la complejidad del término, la cual es poco visible a causa de la simplicidad con la que es definido por el diccionario. Para Frédéric Rouvillois, (2008) el esnobismo es una práctica social determinada por el afán de configurar un ethos distinguido o identidad social coherente con la de aquellos miembros de grupos sociales que gozan de prestigio y diferencia con respecto al grueso de la comunidad. Esencialmente, tal identidad se articula con la búsqueda de ciertos objetos culturales (arte, conocimiento, alta costura, alta cocina, etc.) propios de prácticas sociales restringidas y reservadas a una minoría en posesión de alguna superioridad cultural, sea esta intelectual, económica, estética, etc. La práctica es muy antigua y siempre ha sido vista como un esfuerzo por acceder a derechos gracias a la imitación, algunas veces, afectada de las costumbres propias de los círculos sociales privilegiados.

Esto último explica el valor negativo inherente al término. El ser categorizado como esnob es regularmente una evaluación hecha por un Otro que percibe como falsa la conducta del sujeto. El esnob es visto como un actor ajeno al círculo al cuál se esfuerza por pertenecer y recibe la marca social disfórica. Ahora bien, independientemente de ello, el esnobismo debe ser entendido como una 
forma de vida estructurada sobre un programa narrativo de búsqueda de capital simbólico, fundamentado en un objeto de valor: la distinción representada por la rareza. Regularmente el snob no es más que un actor social interesado en participar en los rituales de iniciación que vinculan con los valores del círculo privilegiado y sus sistemas éticos. Las limitaciones de extensión propias del presente artículo y sus objetivos inmediatos no hacen pertinente profundizar en los pormenores de estos sistemas, pero sí es importante destacar un elemento clave en ellos: la rareza. Para comprender la importancia de este rasgo semántico, se debe tener en cuenta que el esnobismo se inscribe dentro de las dinámicas de consumo de bienes y servicios; específicamente, dentro de lo que Pierre Bourdieu define bajo la categoría de traslación de la estructura de los gustos:

La elevación del nivel de la demanda determina una translación de la estructura de los gustos, una estructura jerárquica, que va de lo más raro - hoy en día Berg o Ravel- a lo menos raro -Mozart o Beethoven-; para decirlo de manera más simple todos los bienes ofrecidos tienden a perder parte de su rareza relativa y de su valor distintivo a medida que crece el número de consumidores a la vez dispuestos a apropiárselos y aptos para ello (Bourdieu, 1990, p. 140).
La dinámica se opone a un principio funcional propio de algunas formas de producción de objetos culturales. Se trata de la adaptabilidad de la oferta a las imperativas de demanda; es decir, el productor de bienes y servicios analiza la lógica interna de las dinámicas de consumo del mercado cultural, con el fin de anticipar el nivel de consumo de sus productos y, obviamente, los beneficios deducibles de ello (Bourdieu, 1990, p. 136). Al determinar qué tanta coherencia tiene lo ofertado con los gustos imperantes, el productor se inserta dentro de lo que, aquí, consideramos las mecánicas de legitimación y sostenimiento de los grupos sociales opuestos a la élite. Desde nuestro punto de vista, esto explicaría la forma de vida snob. Siendo un esfuerzo por apartarse del gusto común, el snob respondería a la traslación de la estructura del gusto, ya que al masificarse la cantidad de objetos culturales antes restringidos a los gustos de grupos elitistas, a causa de factores como la difusión massmediática o de fenómenos menos banalizadores como el descrito por Bourdieu (1990, p. 139): la facilidad de acceder a niveles de escolarización que capacitan para consumir bienes y servicios antes restringidos. De alguna manera, el esnobista buscarían la distinción social dada por aquellos bienes y servicios poco consumi- dos o comprendidos, dada su rareza relativa; es decir, la baja difusión. Bourdieu da un ejemplo interesante:

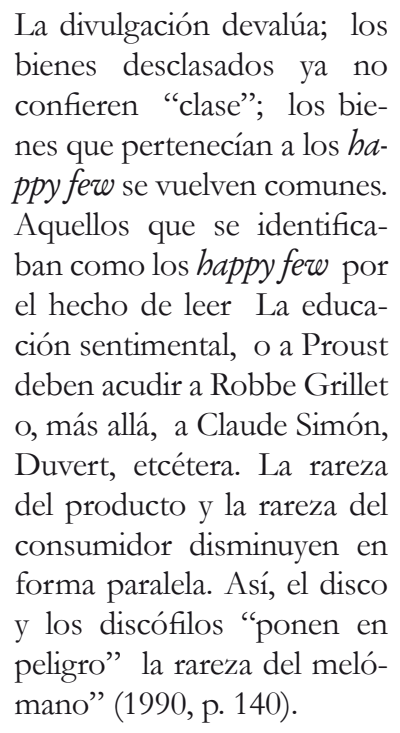
consumidor disminuyen en forma paralela. Así, el disco y los discófilos "ponen en peligro" la rareza del melómano" (1990, p. 140).

El esnobismo funciona bajo el mismo principio. Independientemente del rasgo peyorativo que le es inherente a causa de su búsqueda de la distinción social, en esencia, responde al deseo de configurar un ethos o identidad social basado en la oposición común / diferente. Es esto lo que interesa conservar para los fines del presente artículo.

El calificativo de esnob es usado para desaprobar los gustos del protagonista. El uso responde al sentido básico peyorativo, tal y como lo registra el DRAE y describe Rouvillois (2008); pero, desde el punto de vista del protagonista, confirma la actualización de los objetivos perseguidos. Esto obedece a una de las formas de transfor- 
mación del gusto: "Claro que las diferencias objetivas pueden estar subjetivamente redobladas, y desde hace mucho tiempo los artistas, que se distinguen objetivamente, también tratan de distinguirse: en especial, mediante la manera de ser, la forma, la que les pertenece a ellos" (Bourdieu, 1990, p. 137). Lo que se traduce en un sentimiento de superioridad:

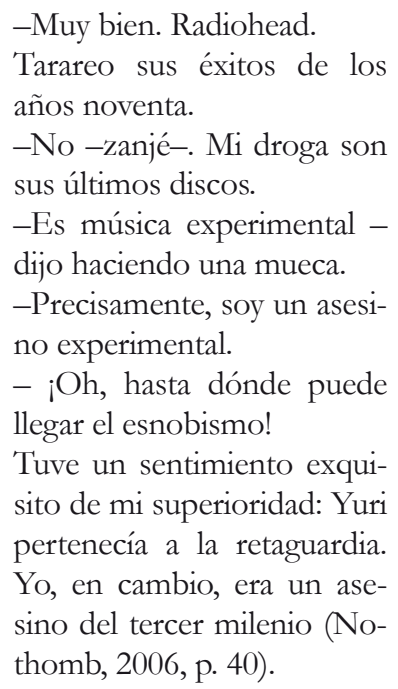

Desde el punto de vista de un público mayoritario, consumidor de bienes y servicios masificados, se es esnobista por interesarse en la rareza propia de ciertas élites culturales. Desde el punto de vista del sancionado, a causa de sus gustos, se adquiere consciencia de hallarse en el camino de la construcción de la identidad superior. En consecuencia, lo que dentro del marco de la cultura es reprobable, para el protagonista es un hallazgo invaluable: "pero descubrí, situada en la comisura del ojo una lágrima" (Nothomb, 2006, p.10-11).

El llanto trasunta valoración positiva. El protagonista da muestras de satisfacción frente a este hecho: "Loco de reconocimiento, mi cuerpo se inclinaba hacia aquella escuálida música como si de una ópera italiana se tratara, tan profunda era su gratitud por, finalmente, haber salido de la nevera. Presioné la tecla repeat con el fin de verificar aquella magia ad libitum" (Nothomb, 2006, p. 11). Dentro del horizonte axio- lógico del protagonista, el calificativo de esnob es inaplicable e inmediatamente opuesto a los semas auténtico y verdadero. Esto hace pensar que la autoinsensibilización de la que él es objeto supone el desplazamiento desde un estado inicial disfórico hacia uno eufórico y potencialmente abierto a nuevas formas de sensibilidad. Se tendría, entonces, un punto de partida determinado por la obligación social de tener una identidad falsa e inauténtica (deber-ser). La interocepción ${ }^{4}$ del protagonista presupone una voluntad opuesta a tal coerción social (querer-no ser). Un segundo estado sería de llegada, configurado radicalmente por la interocepción. Este se muestra determinado por la necesidad de cambio experimentada por el protagonista, que es también experiencia de libertad (no deber-ser), por un lado y, por el otro, sus deseos de recuperar la sensibilidad (no querer-no ser):

Fig. 1

(Disforia completa)
Identidad
Sensibilidad
Simulación y falsedad

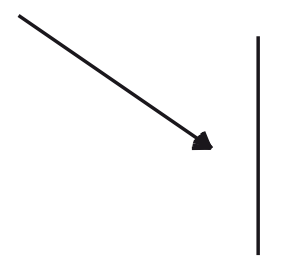

(Más o menos euforia y más o menos disforia) Carecer de identidad Insensibilidad Autenticidad y verdad

4 Dado el carácter de construcción semiótica del actor, hablar aquí de interocepción (percepción de mundo interior o del propio ser) supone la noción de simulacro, pues no se pierde de vista la clara distinción entre persona y personaje. 
La preocupación del sujeto protagonista frente a su anestesia y su conmoción frente a la recuperación de la sensibilidad, gracias a la conjunción con objetos de valor demeritados por el parecer común, desatarán la segunda de las transformaciones. Alcanzado el estado ya descrito, el sujeto ha perdido todo vínculo tímico y axiológico con el universo cultural, la insensibilidad por la que apostó le convierte en un extraño y su identidad impuesta es ahora una no-identidad. Mas, a pesar de ello, no es posible hablar de euforia completa, pues su hacer le lleva a la necesidad de buscar nuevas formas de sensibilidad:

Después comprendí: lo que en adelante me conmovía era lo que no se correspondía con nada común... Mi sensibilidad sólo se abría a sensaciones sin precedente... Desde entonces, ocurrió lo mismo con lo que me hizo las veces de sentimientos: sólo experimentaba aquellos que vibraban más allá del bien y del mal... Se me vio en lugares en los que nunca había ido antes... (Nothomb, 2006, p.12)

El protagonista busca recobrar la sensibilidad gracias a la conjunción con experiencias fuera de lo común. Esto obedece a su deseo (no querer-no ser sensible), pero afecta la aparente libertad ganada (no deberser). En tal estado de cosas, el sujeto abocará un proceso de reconstitución de la identidad, pues así como la insensibilización implicó la pérdida de vínculos, su renovación por otros caminos causará la instauración de una nueva condición del ser: "Nadie me pidió mi carnet de identidad: pude dar el nombre que me dio la gana. Resultó ser Urbano, mi sueño en materia de nombres. A ellos les bastó... En mi ficha, vi que alguien había anotado tirador de élite. Aquello me halagó. Era la primera vez que me calificaban de élite y me gustaba que fuera por un criterio objetivo" (Nothomb, 2006, p. 18). La secuencia citada es el clímax de las búsquedas del personaje que trasiega decididamente por la experimentación sensorial. "El oído me había hecho regresar entre los vivos" (Nothomb, 2006, p. 12), el arte contemporáneo hará lo propio con su visión, la exploración olfativa, al mejor de los estilos de Grenouille, constituirá buena parte de sus ocupaciones; sin embargo, el tacto permanecerá fijado a la componente sexual -terreno con las mayores dificultades, pues una de sus operaciones inaugurales fue darle muerte a la pasión amorosa.

En medio de todas estas ganancias, irá perdiendo los últimos vestigios de su lazo con el universo cultural: es despedido por su irresponsabilidad al conducir, luego de atropellar un anciano -incidente por el cual no manifestó ni el más mínimo de los remordimientos: "Lo que tenía que ocurrir ocurrió: atropellé a un anciano. Nada serio. Mi jefe no opinó lo mismo y me despidió en el acto. Avisó a sus colegas de que no me contrataran, calificándome de peligro público" (Nothomb, 2006, p. 16), y más adelante: "Peligro público, había dicho mi ex jefe (sic). Me pregunté si ése no podría ser un oficio" (Nothomb, 2006, p. 17). La respuesta a su inquietud es saldada en el mismo capítulo, cuando conoce al sicario ruso Yuri. Éste le contacta con el grupo criminal al que pertenece y es puesto a prueba. Los resultados ya se conocen: "tirador de élite" y la euforia que le acompaña, seguida inmediatamente por el bautizo voluntario: Urbano.

De ahora en adelante, el protagonista vivirá las sensaciones más intensas que esta identidad le brinda. Sus sentidos exacerbados con cada homicidio le restituirán en su tan deseado terror de lo vivo. El tacto no escapa al paroxismo, pues resurgirá con la masturbación luego de cada asesinato, experimentando la plenitud del recuerdo de las víctimas. La segunda de las transformaciones se despliega como la orientación del sujeto protagonista hacia el objeto de valor vitalidad restituida gracias a la conjunción entre él y la identidad Urbano. "No hay ejercicio más radical que la voluntad de poderío. Sobre un ser del que nada sabemos, ejercemos el más absoluto 
de los poderes. Y cual tirano que se precie, uno no siente ni un atisbo de culpabilidad. Un exquisito miedo acompaña este acto. Actúa como catalizador del placer" (Nothomb, 2006, pp. 22-23).

La cadena de satisfacciones, posibilitada por la adquisición de la identidad Urbano, entraña la configuración de un nuevo sistema axiológico. Examinarlo requiere tener en cuenta la estructura de esa cadena. Con la nueva condición, el horizonte axiológico del protagonista ubica sus valoraciones fuera del campo ético colectivizado: “... uno no siente ni un atisbo de culpabilidad” y, antes, “...sólo experimentaba aquellos que vibraban más allá del bien y del mal" (Nothomb, 2006, p. 22). La caída completa en lo abyecto retribuye con el placer, lo que es coherente con el interés de recobrar la sensibilidad, lo que es isotópico por implicación ${ }^{5}$ con el semema vida. La aferencia $^{6}$ del sema sensibilidad recobrada realiza inversión de valores. Esto positiviza el acto de asesinar que deriva en la cadena de satisfacciones del protagonista; así, pues, la muerte en la cultura es la vida en la condición ética de este sujeto.

El protagonista como sujeto de hacer se dirige hacia la consecución de un objeto de valor incrementable en el paroxismo sensorial, identificado como la vida recobrada -recuérdese que el actor se lamentaba anteriormente porque "La vida se había convertido en muerte" (Nothomb, 2006, p. 10). Esta "resurrección" dentro del espacio de lo abyecto demanda quitar la vida a los sujetos que pertenecen al universo cultural. El acto allana toda diferencia e, incluso, posiciona éticamente al protagonista, Urbano, más allá de los códigos morales de sus colegas sicarios:

\section{- No entiendo por qué te sientes incómodo -le dije a Yuri-. Por supuesto que estoy dispuesto a cargarme a ese ministro... ¿Desde cuándo me impresiona a mí un ministro? ¿A ti te impre- siona?}

-No. Pero también hay que liquidar a su familia.

—Mejor aún. Me horrorizan las familias...

—Quien dice familia dice niños.

-Bah, niños. Odio los niños. Son malos, estúpidos, egoístas y ruidosos. Y encima hijos de un ministro. De- ben ser la hez de los niños. Me satisface librar al planeta de semejante escoria.

—La esposa de ministro es bastante guapa -dijo enseñándome una foto.

-Sí. No es mi tipo. Y, para variar, me vendrá bien matar a una delgada.

-Urbano eres el peor de todos nosotros, -dijo Yuri con un atisbo de admiración (Nothomb, pp. 51-52).

En la sima de la abyección, el espacio ético define la vida como experiencia sensible basada en el placer del ejercicio del poder (asesinar al Otro y el universo cultural que este representa). Ello presupone la adquisición de una competencia que cualifica axiológicamente al protagonista, que ha pasado de simplemente rechazar los vínculos con el universo cultural al ejercicio soberano de anular al ser social. Si se toma en cuenta el trayecto descrito en la figura 1, la no-identidad da paso a la nueva identidad Urbano y a la sensibilidad reconstituida. Los valores verdad y autenticidad persisten, pero registrando incremento en su carga semántica por intensificación de la

5 El concepto de implicación es un tipo de relación semántica que comunica sememas de taxemas diferentes gracias a lo que Rastier llama elementos aferentes. La implicación en términos rastiereanos es similar a lo que tradicionalmente se entiende como significado connotativo, pero comparte semejanzas con el funcionamiento de la metáfora en su capacidad para establecer analogías entre elementos semánticos diferentes. Sobre esto último consultar el texto La metáfora de Eduardo De Bustos (2000, p. 66).

6 El concepto de sema aferente referencia aquellos rasgos semánticos que dependen del contexto del enunciado. 
euforia. En tal estado de cosas, el protagonista se podría definir como sujeto en plena posesión de sí mismo y completa satisfacción con su ser y estar en el mundo. Ahora bien, esta nueva forma de vida implica un rasgo bastante singular: "Urbano eres el peor de todos nosotros, dijo Yuri con un atisbo de admiración" (Nothomb, 2006, p. 52). Su competencia le impide ser engañado por los falsos valores culturales, los cuales calan tan profundo en el Otro como para generar escrúpulos, incluso en el criminal consumado en el profesionalismo. Como se nota en el diálogo, valores como familia, niñez, belleza gozan de investidura especial para el sicario ruso. La aferencia del sema necesidad de protección parece dimensionar estos sememas, configurando su estado de intocables. Pero, el universo cognitivo del protagonista carece de escrúpulos. Para él, lo auténtico es la experiencia del "terror de lo vivo" que lo restituye en el mundo gracias al paroxismo.

En el enunciado del actor Yuri, el predicado "Eres el peor de nosotros" es oponible al sintagma preposicional "con un atisbo de admiración". Para Descartes, la Admiración es "el primer encuentro con algún objeto (sic) nos sorprende, porque lo creemos nuevo, o muy diferente de lo que conocíamos antes, o bien de como suponíamos que debía ser, lo admiramos y nos asombramos ante él" (1997, p. 373). Esto permitiría afirmar que el sicario ruso reacciona frente a lo inusitado de la conducta, pero a su vez reconoce en Urbano un ideal, pues en este los escrúpulos morales, que aún vinculan al sicario promedio con el universo cultural, son remplazados por los principios de la ética profesional abyecta. Esto hace eco de lo explicado por Elisabeth Rallo (Rallo, Fontanille \& Lombardo, 2006, pp. 17-26) cuando, siguiendo a
Herman Parret, dice que la admiración hace parte de las pasiones impulsadoras del deseo y la intensión o la necesidad de saber sobre el objeto o persona admirada. La admiración es una de las pasiones que llevan a la empatía. En tal medida, es posible establecer relaciones entre la admiración de Yuri y la valoración frente a la compentecia profesional de Urbano. En posición de evaluador regido por el sistema de valores del universo sociocultural, Yuri sanciona negativamente: "el peor". Sin embargo, la sanción comporta ambigüedad, dado que él mismo se sabe perteneciente a la colectividad de lo abyecto, "el peor de todos nosotros". Esto explica la estimación frente la competencia de Urbano: él puede hacer lo que los demás no, respondiendo perfectamente al espacio ético del abyecto. La eficiencia y el profesionalismo son rasgos que definen al protagonista y lo convierten en un ideal difícil de alcanzar.

Fig. 2

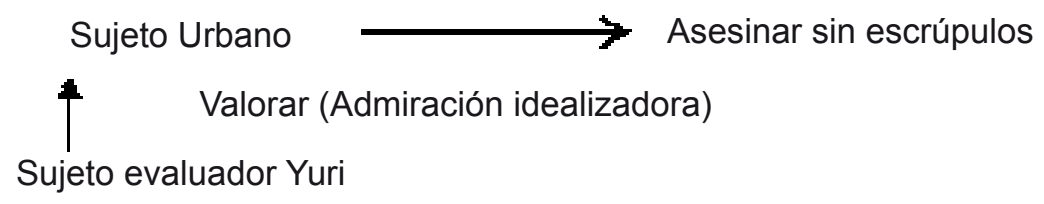


La particularidad de esta evaluación ofrece otros puntos por considerar. Dado que el sujeto Urbano está en posesión satisfactoria y plena de sí mismo, lo que se dimensiona como el ideal de lo abyecto, es posible considerar la existencia de un objetivo o meta modela- dora del ser: la adquisición de la identidad auténtica. Esto entraría en concomitancia con el deseo de recobrar la sensibilidad, pues ser Urbano conlleva a la práctica del asesinato, y esta al paroxismo garantizado por la competencia que le define como sujeto ideal de lo abyecto. El protagonista, pues, se encuentra determinado por una nueva obligación, esta vez contraria a las coerciones sociales (deber-no ser), en tanto que la identidad Urbano se instala como el contrario de la identidad social.

Fig. 3

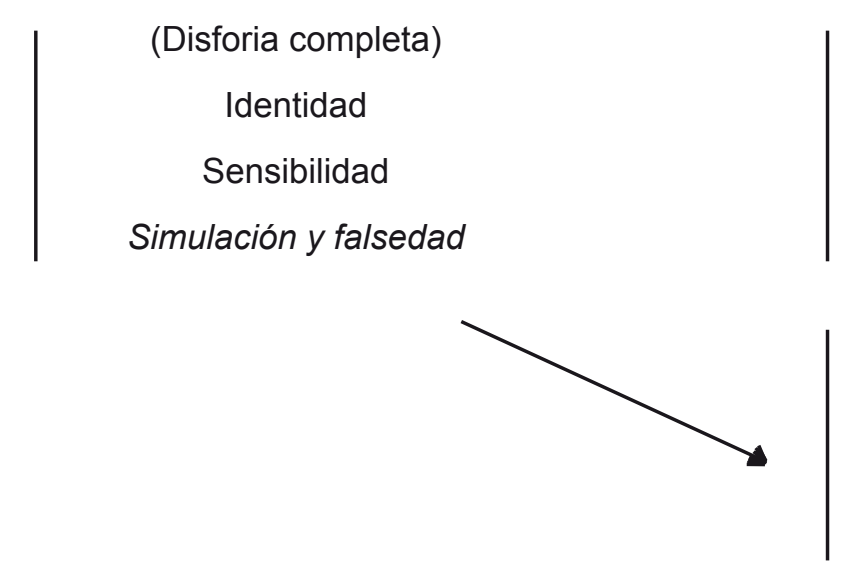

A estas alturas del análisis, es plausible afirmar que el relato trasunta convergencia entre identidad y condición ética. La oposición estructural vida / muerte supeditada al trasegar tímico y axiológico del protagonista implica la aferencia del sema derecho a. El sujeto decide quien tiene derecho a vivir o no. Esto, además, supone una inversión semántica en el universo cognitivo, pues lo vivo en la cultura se define como muerto $\mathrm{y}$, por lo tanto, digno de ser eliminado, mientras que el asesinar se categoriza como despertar de la vida, manifestada en la sensi- bilidad reconstituida. La ética de lo abyecto conlleva, dentro del universo cognitivo del protagonista, a hacer justicia en su más pura forma lógica: dado un $A$ igual a un $B$, ambos deben ser tratados igual (Perelman, 2007, 94-101). En otras palabras, siendo la cultura cronotopo de la falsedad y la muerte, entonces quienes le habitan y legitiman debe ser tratados como muerte: "Me satisface librar al planeta de semejante escoria" (Nothomb, 2006, p. 51).

Sin embargo, el recorrido del personaje no acaba aquí.
Una última transformación opera. El trasegar de la insensibilización llevó a la instauración de la nueva identidad, ahora, la búsqueda de satisfacción confrontará a la suplantación de aquella por una más auténtica, y nuevamente ocurrida por auto-asignación: "No era mi primogenitura a la que había bautizado así sino a mí mismo. Si aquel nombre me había venido a los labios sin ninguna reflexión previa, debía corresponder a algo profundo. Para un asesino a sueldo, decidir de repente que te llamas Inocencio es más que un cambio de nombre, 
es un cambio de identidad" (Nothomb, 2006, p. 90). Lo que fuera, para él, un trabajo regular ha comportado un rasgo diferencial que reconfigura su universo cognitivo y, por ende, su espacio ético. El protagonista se conjunta con la identidad Inocencio. Lo que abre la puerta a esta transformación es figurado en la secuencia del homicidio del ministro y su familia. El protagonista, todavía siendo Urbano, debe, muy a su pesar, abandonar el espacio hasta ese momento utópico de la ciudad. La novedad del cambio de espacio arrastra varias consecuencias.

La puerta de la cocina estaba abierta. En el campo, nadie desconfía. No resistí la tentación de abrir la nevera. Por desgracia, no contenía la leche de granja que me habían hecho desear los paisajes campestres. Había mucho cero por ciento en aquellas vituallas. Asqueado, me consolé con un trago de vino tinto bebido de la botella. De puntillas, subí la escalera de madera de la morada. Menos mal que había examinado sus detestables provisiones, si no, la belleza del lugar me habría hecho simpatizar con aquella gente. (Nothomb, 2006, p. 55)

Se notará el cambio. El protagonista pasa de repudiar el espacio campestre: "¡Mierda, es en el campo!" (Nothomb, 2006, p. 53), a la clara euforia por el contacto con él: "Por desgracia, no contenía la leche de granja que me había hecho desear los paisajes campestres (sic)" y, antes, "Hay que ver lo bonito que es el campo al amanecer. Nunca había visto esa capa de vapor sobre la tierra" (Nothomb, 2006, p. 54). El cambio de opinión remite, como se puede notar, a la oposición naturaleza / cultura. El deseo que despierta la conjunción con lo natural se explicita en el deseo de tomar "leche de la granja" y en la acción de beber "un trago de vino tinto" directamente de la botella. Leche sin el procesamiento cultural, "cero por ciento", que le priva de la autenticidad de sus propiedades naturales, vino que se toma sin la mediación de la copa, tan asociada a los protocolos. El rechazo explícito a las normas de etiqueta y productos culturales no es extraño, recuérdese que todo ello empieza con la renuncia a la identidad culturalmente impuesta, lo único diferente consiste en la oposición espacial que viene a ampliar lo que ya se venía perfilando en otros ámbitos.

Algo más aviene con ello, el contacto con lo natural genera lo que en el espacio urbano era imposible, empatía. Esta es identificable con el efecto producido en el sujeto, gracias a la presencia de la novedad; en palabras de Descartes: "porque lo creemos nuevo, o muy diferente de lo que conocíamos antes, o bien de como suponíamos que debía ser" (1997, p. 373). La novedad del espacio natural emerge como locus amoenus donde se actualiza un deber-ser frente al cual no se puede establecer ningún tipo de polémica: "En el campo, nadie desconfía. No resistí la tentación de abrir la nevera. Por desgracia, no contenía la leche de granja que me habían hecho desear los paisajes campestres" (Nothomb, 2006, p. 55). Con esto, se confirma lo afirmado de Rallo, cuando dice que la admiración hace parte de las pasiones inductoras del deseo y la necesidad de saber sobre el objeto o persona admirada (Rallo, Fontanille \& Lombardo, 2006, p. 20). Esto, evidentemente, ha conducido al protagonista a idealizar y anticipar una conjunción eufórica con un objeto de deseo coherente con el locus amoenus recién descubierto. La empatía es un impedimento para ejecutar el asesinato. Tan sólo la comprobación de la incompatibilidad entre su sentido de lo ideal y la constatación de la identidad culturalmente modelada del grupo social designado como su blanco le permite seguir adelante. Así que, sin escrúpulos, reanuda su programación. Luego de haber ejecutado a tres de los miembros de la familia, procede con el ministro y su hija. Para su sorpresa, encuentra a la chica amenazando al padre con una pistola. La razón es que éste 
tomó el diario personal de su hija y ella, enfurecida por lo que le parece un ultraje a la intimidad, hace el reclamo. El padre admite haber leído el texto y su hija lo mata.

\footnotetext{
- Robarle un diario íntimo a una persona es una aberración.

$\ldots$

— ¿Cómo? ¿Lo has leído?

- Por su puesto. Si no, ¿para qué iba a cogerlo? Aquello fue demasiado para ella. Vació su cargador. El ministro, estupefacto, resbaló en el agua, muerto (Nothomb, 2006, pp. 58-59).
}

El protagonista cumplirá el objetivo. Ultimará a la chica, quién, para sorpresa, no mostrará señales de sobresalto o temor. Sucederá lo inesperado, lo que hasta el momento $\mathrm{y}$ en concomitancia con la identidad Urbano había retribuido con la vitalidad, la sensibilidad reconstituida, no funciona. Lejos de todo ello, el tratar de generar la euforia masturbatoria acaba en frustración: "No podía esperar hasta París. Escondido tras unos matorrales, procedí. $\mathrm{Cu}-$ riosamente, no experimenté tanto placer como esperaba... Asqueado, me pregunté si no me habría convertido en un pervertido, que sólo alcanza la satisfacción auténtica con viejas pretenciosas o trajes de chaqueta" (Nothomb, 2006, 59-60). Seguirá intentándolo hasta darse cuenta de su inu- tilidad, y ello llegará hasta las últimas consecuencias, cuando su incapacidad le impedirá cumplir con otro trabajo: "Me di cuenta de que, ante la idea de matar, no experimentaba ninguna alegría ni excitación: sólo el fastidio de un lector apasionado interrumpido en su lectura por una terea doméstica" (Nothomb, 2006, p. 85). Ocurre, pues, la transformación.

No tenía ningún sitio donde dormir y eso me venía bien, estaba demasiado excitado por mi nueva identidad para tener sueño. En el bar, bauticé a Inocencio con whisky. A quien quería escucharlo o no, no perdía ocasión de declararle que me llamaba Inocencio. Luego rompía a reír. Algunos creyeron que acababa de ser absuelto. Todos supieron que estaba borracho. Un nombre nuevo se te sube a la cabeza (Nothomb, 2006, p. 94).

Se notará el desplazamiento tímico hacia lo implicado por la adquisición de la nueva identidad. Sobre el origen de tal fenómeno, la enunciación ofrece evidencias:

No había pensado en ello al inventarme que me llamaba Urbano, ese nombre le iba perfectamente al asesino de las ciudades cuya falta de sentimientos autoriza a liquidar a desconocidos con total urbanidad. Había bastado una excursión campestre para que aquella identidad se resquebrajara, una golondrina para volverla inoperante, un par de ojos hermosos para imponerme otra Nothomb, 2006, p. 91).

La secuencia rememorada por el protagonista instala un nuevo actor con el rol de manipulador. Confrontó la mirada de quien ostenta el estado de pureza y autenticad, no la deleznable familia tan imbuida de las marcas de lo cultural: “...tu perfil puro y severo, tu soberbia indignación, tus disparos convirtiendo ese baño de espuma en baño de sangre" (Nothomb, 2006, p. 78). La presencia del manipulador termina por hacer irrealizable la conjunción con la euforia, desplazando tímicamente al protagonista hacia "aquel nombre" que le "había venido a los labios sin ninguna reflexión previa" y que "debía corresponder a algo profundo". El sentido del lexema Profundo en el contexto de la obra (texto enunciado), resulta fundamental para comprender la identidad y naturaleza de este manipulador. Tal hecho autoriza a tomar una postura metodológica ceñida a la inmanencia de lo enunciado. Es por ello que se adopta, aquí, uno de los argumentos esgrimidos por Algirdas J. Greimas cuando decidió analizar lo que él llamó la cólera francesa: "Es notorio que los lexemas se presentan a menudo como condensaciones que, por poco que aclaren, 
cubren estructuras discursivas y narrativas muy complejas. (...) las descripciones lexemáticas pueden constituir, de forma económica, modelos de previsibilidad para análisis discursivos" (Greimas, 1989, p. 255). Ahora bien, es preciso aquí aclarar que la reconstrucción de la estructura discursiva del manipulador, a diferencia del modelo de la cólera, postulado por Greimas (1989, pp. 255-280), es un sistema específico y particular, lo cual no impide acudir al tipo de fuente empleada por Greimas: las condensaciones compiladas en un diccionario autorizado.

Según el DRAE, el semema de profundo subsume entre sus acepciones a: "lo más íntimo de una persona". La definición de diccionario pone frente a la emergencia de un sema clave: lo intimo. Esto permite establecer isotopía con el semema propio, ya que, también en lengua, ${ }^{7}$ remite a aquellos que es natural, no postizo ni artificial y que es característico, peculiar de cada persona o cosa. En consecuencia, es factible hablar de preyacencia como categoría sémica más inclusiva; lo que, en otro nivel, equivaldría a afirmar que si al protagonista le vino a los labios no es porque fuese algo ajeno a su ser, sino la manifestación del secreto que le habita. "(...) no había visto nada secreto. Lo íntimo hoy es el Grial" (Nothomb, 2006, p. 81). La manipulación ocurrida es más la encarnación de aquellos deseos profundos que movían al protagonista a buscar la autenticidad de su ser; cosa que inició con la renuncia a la identidad impuesta y que, como ya se explicó, se constata en la euforia alcanzada con la autoasignación del nombre Inocencio.

Lo anterior conlleva a repensar las dos primeras transformaciones, pues la cuestión respecto a esa motivación interna exige ahora corroborar una posibilidad: que el protagonista se encuentre sobredeterminado por una convicción de la cual no era plenamente consciente. La enunciación ofrece pistas al respecto. El semema intimo paradigmáticamente se correlaciona con la oposición autentico-verdadero vs simulación-falsedad, pues los semas natural, no-postizo, no-artificial, característico y peculiar definen por oposición excluyente al semema simulación-falsedad. Mas, se pueden hacer otras inferencias. Ya en la oposición espacial cultura / naturaleza hay implicaciones de los opuestos autenticidad / simulación -recuérdese el desprecio que manifiesta el protagonista hacia lo culturizado -y se le tiene además dentro del sistema paradigmático que define al semema intimo. De lo anterior, se concluiría que los resultados derivados del encuentro con la mirada del actor-hija del ministro son la concretización de un encuentro que ya venía siendo perfilado y anticipado por el deseo del protagonista, una suerte de manipulación evidenciada con la revelación. Un sujeto, el protagonista, es manipulado para conjuntarse con un objeto de valor, la identidad auténtica; pero siendo el manipulador coincidente con sus propias aspiraciones, las cuales se proyectan en la figura del actor que él llama Golondrina (la hija del ministro). El carácter proyectivo de este actor se puede acreditar, si se considera la secuencia donde un ave entra a morir en el apartamento del protagonista; situación en la que, extrañamente, el actor halla coincidencias con el evento del asesinato de la hija del ministro -el nombre de Golondrina precisamente emerge de aquí: "Sobre la cama, abracé el pensamiento amado. El pájaro-chica depositaba su revólver y se ofrecía a mis besos. Me tenía a raya con sus ojos armados, a veces posaba

$7 \quad$ El concepto de sistema funcional de la lengua es propuesto por François Rastier. Alude a los significados estandarizados y reconocidos como propios de la semántica más generalizada de un idioma. Es a lo que muy imprecisamente se le llama significado denotativo. Estos significados son el objeto de estudio de las investigaciones lexicográficas y de las cuales surgen, entre otro tipo de obras científicas, los diccionarios (Rastier, 2005, p. 67). 
mis labios sobre sus párpados" (Nothomb, 2006, p. 77).

La estructura completa asume la forma de cadena de presuposiciones determinada por la convicción. Registrando, en concomitancia, el incremento gradual de la euforia de pasar de una identidad a otra, de una menor a una mayor autenticidad.

Fig. 4

$(+)$

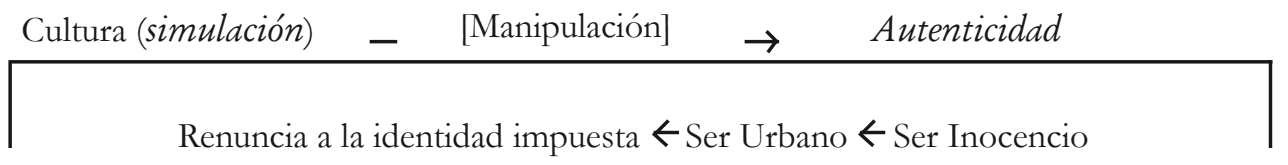

A nivel del sistema de valores, la estructura la soportaría un juego de oposiciones categoriales, a pesar de la gradualidad que supone tanto el incremento tímico como el paso de la transposición del manipulador a su manifestación en la proyección. La oposición fundamental vida / muerte, que antes se explicara, articularía gran parte del trayecto y a las categorías menores que se han estado explicitando en las figuras 1 y 3. Mas, cabe tener en cuenta dos aspectos antes de esquematizar. En 3, el trasegar llevaba del carecer de identidad a la identidad auténtica. Dado que la tercera transformación también comporta paso de la menor a la mayor autenticidad y que el encuentro de la máxima sensibilidad supone la euforia causada por la identidad Inocencio, convendría examinar la posición que debe ocupar la identidad Urbano.
Algo comparten Urbano e Inocencio y es el incremento tímico, sumado al valor de autenticidad vertido en ambos en contrariedad a las coerciones sociales que exigen convertirse en simulación y falsedad. Por otra parte, la auto-asignación de tales identidades permite la realización del deseo de recobrar la sensibilidad que impulsa al protagonista. Dadas estas coincidencias, se cree que ambas ocupan la posición de identidades auténticas en el recorrido narrativo.

Por otra parte, cabe considerar un elemento adicional. La violación a la intimidad fue la razón por la cual la hija asesinara al padre, la protección del mismo valor es lo que motiva la última de las acciones del protagonista: "Acepto morir para proteger un misterio que se me escapa" (Nothomb, 2006, p. 103). Si se toma en cuenta lo dicho anteriormente sobre las acepciones de la categoría sémica profundo, las relaciones semánticas con el valor autenticidad salen a flote. La enunciación lo mostraría cuando el protagonista decide comerse el diario de la chica: "Llevo hasta el paroxismo, la relación que uno puede tener con un texto: lo he leído hasta los huesos y ahora, sin metáfora lo devoro... el sabor tiene su interés: recuerda el de la hostia" (Nothomb, 2006, p. 103). La absolución llega a él a través del diario. El acto de comerlo equivale a lo que en la ceremonia católica es comer el cuerpo y sangre transustanciados de Cristo. La figura de la "hostia" lo confirma: el diario es la esencia de la chica que constituye el "paroxismo" de la experiencia sensible y la plenitud en la autenticidad de la identidad. 
Fig. 5

(Disforia)
Muerte
Cultura
Sensibilidad culturizada
Simulación y falsedad
T
(Menos euforia)
Degradación
Culturizarse
Sensibilidad debilitada
Menos autenticidad y verdad
El sistema de valores del
protagonista opone categorial-
mente la falsedad que conduce
a la asignación de identidades
simuladas en el sistema de la
cultura y que son contradicto-
rias con la intimidad que tra-
sunta la esencia del ser. El reco-
rrido de lo abyecto es la cadena
que llevará a la revelación de la
intimidad perseguida y que se
corresponde con la autentici-
dad del ser en la identidad.

\section{Conclusiones:} implicaciones de la situación de lectura

La novela como praxis discursiva es definible como un hacer epistemológico y espacio al interior del cual se configura un enunciatario. Para teóricos como Courtés (1997, p. 360) ello implica la manipulación desde el saber, mientras que

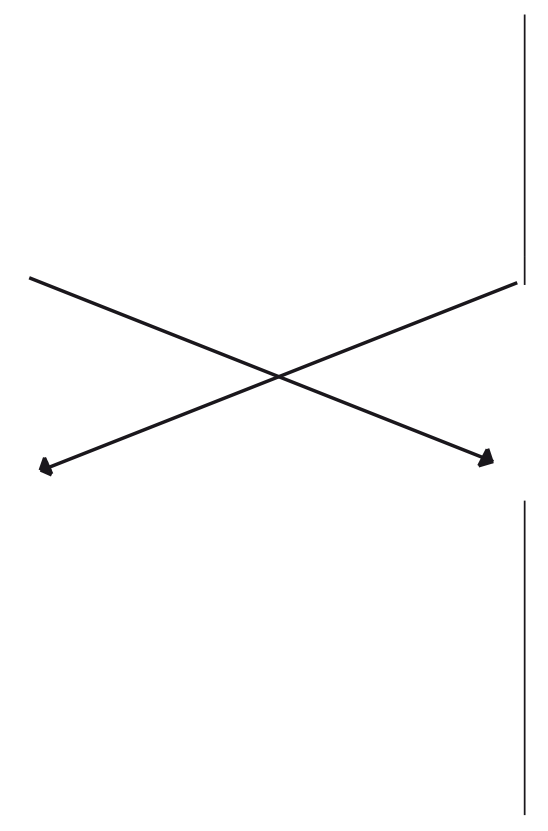

(Más euforia)
Vida
Naturaleza
Sensibilidad reconstituida
Autenticidad y verdad
(Más o menos euforia)
Revitalización
Contra-cultura
Anestesia
Mas Autenticidad y verdad

Reflexión 1. Como hacerpara autores como el Greimas de Del sentido II (1989, pp. 180-181) no toda manipulación supone un enunciatario motivado por el deseo de convencer al Otro (hacer-creer). Esta discusión cobra gran vigencia, tratándose de la novela de Amélie Nothomb. El fuerte cariz ideológico de su puesta en discurso sugiere la presencia de intencionalidad argumentativa manifestada de modo narrativo. Sin embargo, es difícil sostener esto, por lo menos dentro de los alcances de este texto. Ahora bien, una cosa sí es incuestionable, como praxis discursiva, busca comunicar (hacer-saber) una historia a un enunciatario - la novela de Nothomb hace esto como muchas otras. Partiendo de esta condición mínima (Eco, 1992, pp. 237-249) se desarrollan las siguientes reflexiones: saber, la novela de Nothomb obedecería al esquema básico de la búsqueda. Un enunciador se dirigiría a conjuntar un enunciatario con una historia. Lo particular del caso estribaría en el embrague entre el actor protagonista y el narrador (narrador homodiegético protagonista), sumado al recurso estilístico con que cierra la novela: "Muero mano con mano, ya que escribo... Este texto se detendrá en el momento exacto de mi muerte". (Nothomb, 2006, p. 105) La metadiégesis busca la manera de hacer que el universo narrativo "invada" la realidad que circunscribe el acto de la lectura. El objetivo es simple, generar efecto de realidad. Esta articulación de estrategias da pie a ciertas conclusiones. El embrague escamotea 
las distancias entre enunciado y situación de producción del discurso, lo cual genera el simulacro de la comunicación personal. La metadiégesis se propone lo mismo respecto a la situación de lectura. Dado que el protagonista decidió comerse el diario con tal de proteger su valor íntimo y que opta por dejar testimonio de su acción en un segundo texto que, por efecto del recurso, se propone como el mismo que se está leyendo, es factible un segundo embrague entre el narratario y el enunciatario. Se configura, por tanto, un lector que acepta el contrato implícito a la comunicación personal: la confidencia.

El contexto de producción de ese segundo texto transcurre en el espacio de reclusión. El protagonista es capturado por la organización criminal para la que trabaja a causa de no entregar el diario y es amenazado de muerte. Teniendo esto en cuenta, el que tuviese acceso al escrito muy posiblemente sería uno de los captores y, por lo tanto, el lector también. Lo interesante de ello es que éste se configura como uno de aquellos que violan la intimidad, un perpetrador. Si el enunciatario lo es, se inferiría que la situación de lectura también, dado que el acto de la enunciación supone un sujeto que la recepciona.
En tal estado de cosas, la situación de comunicación no consiste meramente en poner en conocimiento una historia, sino que además supone el mostrar que el actor que lee es uno de aquellos que se ubican fuera del espacio que implica la autenticidad, la identidad y la intimidad; lo que por extensión englobaría al lector empírico (nosotros que leemos la novela), esto nos convierte en uno más de los perpetradores, en uno más de los violadores de la intimidad.

Reflexión 2. Ahora bien, no sólo somos perpetradores de la intimidad, sino también los destinatarios de una confidencia y un testamento nacido de la convicción, porque, a fin de cuentas, todo texto configura un lector modelo (Eco, 1993, pp 73-95) y, en tal sentido, una intecionalidad comunicativa. Si somos los perpetradores, somos también los captores de quién conoce la verdad. Pero, quién redacta busca también perpetuar el legado de su manipulador:

\footnotetext{
Con Golondrina, la historia había empezado mal, pero termina de un modo inmejorable, ya que no termina. Me muero por habérmela comido, ella me mata en mi vientre, suavemente, con un mal tan eficaz como discreto. Muero mano con mano, ya que escribo: la escritura es el lugar donde me enamoré de ella. (Nothomb, 2006, p. 105)
}

De esto, resulta demostrativo la auto-asignación que lleva a la conjunción gradual con la autenticidad. Urbano e Inocencio no sólo son nombres, sino también símbolos propios de una forma de vida institucional: la iglesia católica. Nombres emblemáticos de una responsabilidad: el vicario de Cristo. El protagonista oficia como una especie de evangelista de una religión, cuyo centro de culto es la autenticidad, y el camino a tal verdad es la renuncia al universo cultural; cosa que es sólo posible por amar-devorar la esencia transustanciada del manipulador "mesiánico": Golondrina. Acceder a la expiación demanda la muerte que purifica en la comprensión de la palabratestimonio, cuyo eje temático es el respeto a la intimidad y la renuncia a la cultura, que es simulación... La propuesta no es nueva. En el estudio realizado a la obra de Bustos Aguirre (Chico, 2013, pp. 155159), la realización ética del sujeto corre por cuenta de una voluntad que se automanipula y se dirige con determinación a alcanzar un estado de perfección ética: la inocencia. Tal acción se representa como una búsqueda racional y autocrítica, asumiendo la responsabilidad por lo actos propios, sin ello implicar culpabilización (Chico, 2013, pp. 142, pp. 155156). Sin embargo, algo distancia las propuestas éticas de 
Nothomb y Bustos. Para este último, la realización ética demanda un ser y hacer-para sí $y$ el Otro, lo que supone reconsideración de los vínculos con la alteridad: "Inocencia es no gozar con la muerte/destrucción del Otro: Inocencia es no convertir la muerte/destrucción en espectáculo" (Chico, 2013, p. 142). La propuesta ética de Nothomb está más cerca de la nietzscheana, pues es más bien un ser y hacer-para sí, una ética egocentrada que instrumentaliza al Otro. En todo caso, pese a las diferencias algo parece evidenciarse y es que, por lo menos desde el discurso literario, es una recurrencia la búsqueda de formas de realización ética fuera de las fronteras de la cultura ¿moderna?, ¿aquella donde la vida se convierte en espectáculo y, por ende, en la hipocresía del adaptarse a las coerciones sociales fundadas en la falsedad? Esto es ya un cuestionamiento que se abre a nuevos análisis. El discurso literario -por lo menos el de estas dos obras -podría estar dando anuncios de una necesidad propia de nuestras culturas occidentales modernizadas.

\section{Referencias}

Bourdieu, P. (1990). La metamorfosisi de los gustos. En P. Bourdieu, Socilogía y cultura (págs. 133 - 141). México D.F.: Grijalbo.

Bustos De, E. (2000). La metáfora. Madrid: Fondo de cultura económica.

Chico Quintana, R. (Septiembre de 2013). La inocencia Configuración semiótica de una nueva condiciónético existencial en la obra poética de Rómulo Bustos Aguirre. Bucaramanga, Santander, Colombia: Universidad Industrial de Santander.

Courtés, J. (1997). Análisis semiótico del discurso (Primera ed.). (E. Ballón Aguirre, Trad.) Madrid: Gredos.

Cuche, D. (2002). La noción de cultura en las ciencias sociales. Buenos Aires: Nueva Visión.

Descartes, R. (1997). Las pasiones del alma. Madrid: Tecnos.

Durand, G. (2004). Las estructuras antropológicas de lo imaginario. México D.F.: Fondo de Cultura económica.

Eagleton, T. (1991). Ideology and introduction. New York: Verso.

Eco, U. (1992). Los límites de la interpretación. (H. Lozano, Trad.) Barcelona: Lumen.

Eco, U. (1993). Lector in fábula. Barcelona: Lumen.

Fontanille, J. (28 de mayo de 2004). Texto, objetos, situaciones y formas de vida. (H. Rosales Cuevas, Trad.) Bucaramanga. Recuperado el 25 de septiembre de 2011

Fontanille, J. (Marzo de 2007). Semiótica de los textos y los discursos. (H. Rosales Cuevas, Trad.) Bucaramanga.

Greimas, A. J. (1989). Del sentido II. Madrid: Gredos.

Nothomb, A. (2006). Diario de Golondrina. (S. Pàmies, Trad.) Barcelona: Anagrama. 
la palabra

Panier, L. (2003). Análisis semiótico del discurso. Analyse semiotique. (H. Rosales Cuevas, Trad.)

Perelman, C. (2007). El imperio retórico (Primera edición ed.). (A. L. Gómez Giraldo, Trad.) Santafé de Bogotá: Norma.

Rallo, E., Fontanille, J., \& Lombardo, P. (2006). Dirionnaire Des Passions Littéraires. Paris: Belin.

Rastier, F. (2005). Semántica interpretativa. México: Siglo xxi.

Rouvillois, F. (2009). Historia del esnobismo. Buenos Aires: Claridad. 